Article

\title{
Theory of Place in Public Space
}

\author{
Mark Del Aguila ${ }^{1, *}$, Ensiyeh Ghavampour ${ }^{2}$ and Brenda Vale ${ }^{3}$ \\ ${ }^{1}$ Department of Architecture, University of South Australia, Adelaide, SA 5000, Australia; \\ E-Mail: markdelaguila@gmail.com \\ 2 Urban Entrepreneur, Auckland 1072, New Zealand; E-Mail: eghavampour@gmail.com \\ ${ }^{3}$ School of Architecture, Victoria University of Wellington, Wellington 6140, New Zealand; E-Mail: brenda.vale@vuw.ac.nz \\ * Corresponding author
}

Submitted: 22 January 2019 | Accepted: 6 March 2019 | Published: 30 June 2019

\begin{abstract}
Place as a theory fails to clearly articulate linkages between meaning and physical settings for chosen activities in public space. In addressing these issues, the meaning of user behaviour in public space is described by affective and cognitive images of the physical setting; a theoretical conceptualisation of individual experiences which include overlapping social, cultural, and educational contexts. The results of a survey of 160 users across four public spaces found that affect framed cognitive evaluations of design elements for anticipated behaviour. A two-stage process suggesting place-making in design need to shift emphases from articulating preferences to enabling interpretation and opportunity. Within this theoretical framework, the argument is presented that a focus on aligning design with public expectation at a point in time will lead to temporal popularity of location, to popular places that will be presented for redevelopment at some future point in time when their popularity declines.
\end{abstract}

\section{Keywords}

affect; behaviour; cognition; facet theory; place-making; public space; theory of place

\section{Issue}

This article is part of the issue "Public Space in the New Urban Agenda: Research into Implementation", edited by Michael W. Mehaffy (KTH Royal Institute of Technology, Sweden), Tigran Haas (KTH Royal Institute of Technology, Sweden) and Peter Elmlund (Axel and Margaret Ax:son Johnson Foundation, Sweden).

(C) 2019 by the authors; licensee Cogitatio (Lisbon, Portugal). This article is licensed under a Creative Commons Attribution 4.0 International License (CC BY).

\section{Introduction}

While observations of place, placelessness, identity and sense of place are described in the literature and complexities of methodological innovations and computer algorithms in place-making are debated, knowledge of the process of how individual and shared meanings of physical spaces are generated is limited (Carmona, 2015; Cilliers \& Timmermans, 2014; Lewicka, 2011; Liu \& Freestone, 2016). By collating theoretical knowledge of place with experimental work in affect and cognition, and field research in place dependence, it is argued that mental image in the theory of place is comprised of affective and cognitive associations with physical settings and activities in those settings.

\section{Theory}

Place-making as a design practice has its origins in Relph's (1976) description of place-making as a process of creating place which occurs authentically and unselfconsciously in the interactions between people and physical environments. In Relph's work, this description of place-making along with descriptions of placelessness, insideness, outsideness, identity, sense of place, essence of place, etc., were articulated for research to improve knowledge on the theory of place. This knowledge would then inform methodologies for "the maintenance and manipulation of existing places and the creation of new places" (Relph, 1976, p. 44). However, the terminology proposed for research to expand the body of knowl- 
edge about place has been interpreted as theory in practice and the requisite theoretical work has not kept pace with the evolving methodologies in place-making (Lewicka, 2011; Liu \& Freestone, 2016). This has resulted in: (1) "no blueprint for planning public places, and no formula for successful participatory processes" (Cilliers \& Timmermans, 2014, p. 427), with methodologies tailored to each new situation, and (2) an absence of a theoretically driven knowledge base with interactions of physical appearance, activities, and meanings described using detailed taxonomies of case studies (Carmona, 2015).

"Physical appearance, activities, and meanings are the raw materials of the identity of places, and the dialectical links between them are the elementary structural relations of that identity" (Relph, 1976, p. 48). These identities are embedded in the "experience, eye, mind, and intention of the beholder as much as in the physical appearance of the city or landscape" and shared (in part) because "we experience more-or-less the same objects and activities and because we have been taught to look for certain qualities of place emphasised by our cultural groups" (Relph, 1976, p. 45). Spaces separated through experiences; experiences which transform space into place by "a particular system of physical features, activities, and meanings" (Relph, 1976, p. 49). A weaving together of "the physical environment, human behaviours, and social and/or psychological processes" (Stedman, 2003, p. 671) and while "place, person, time, and act form an indivisible unity" (Wagner, 1972, p. 49), it is not a territory defined by that intersection (Canter, 1997). It is a snapshot observed within individuals on-going experiences, a snapshot shaped by personal, social, and cultural histories. Identities frequented and placeless spaces defined in time (Canter, 2008; Motloch, 2000) with "as many identities of place as there are people" who recognise a space as a separate entity (Narin, 1965, p. 78, as cited in Relph, 1976, p. 45). The recognition of spaces as separate entities, with spaces frequented described as places dependent on two components of goal-orientated behaviour: (1) the quality of the place in terms of social and physical resources to satisfy goal-directed behaviour, and (2) how it compares to other alternative places (Pretty, Chipuerb, \& Bramston, 2003). Comparisons described as involving both the emotional bonds to the setting and the activities afforded by the setting (Zhang, Matsuoka, \& Huang, 2018) that are not always conscious or continuous but come into play when circumstances heighten awareness (Stokols \& Shumaker, 1981).

This perspective suggests that the positive affective content of the bond results from successful goal pursuit, the cognitions consist of expectations of goal attainment based on past experiences, the behaviour expressed is repeated place use, and the place focus is social or physical, depending on the particular goals sought....This can lead to place dependence, a type of attachment in which individuals value a place for the specific activities that it supports or facilitates. (Scannell \& Gifford, 2010, p. 6)

This is consistent with Rapoport's (1982) description of an "affective image" as the organism's initial interaction with an environment which frames subsequent analysis, evaluation, and decisions about a physical setting. Something Motloch (2000) referred to as setting appraisal followed by a second inter-related process of evaluation. While Kaplan $(1987,1995)$ reasoned that perception is related to mental representation, a gradual process comparing past experiences with the present, studies have found that affective images are not preceded by a cognitive process but are precognitive and constitute the initial level of response (Dixon, 1981). Controlled experimentation on preferences, attitude and impression formation, decision-making, and clinical phenomena indicate that "affective reactions to stimuli are often the very first reactions of the organism...can occur without extensive perceptual and cognitive encoding, are made with greater confidence than cognitive judgements, and can be made sooner" (Zajonc, 1980, p. 151). These arguments are supported by GIS mapping of behaviour in public space which found materiality of design elements less important than their context indicating that decision making, be it affective and or cognitive, is part of actualised behaviour in public space (Ghavampour, Del Aguila, \& Vale, 2017).

\section{Hypothesis}

In theory, place is defined by an alignment of mental image, behaviour, and physical setting. A model within which mental image has an implicit temporal dimension where past experience is reflected in affective and cognitive responses to current physical settings. Within this framework, it is hypothesised that anticipated behaviour in public space can be described by affective and cognitive responses to physical settings and the design elements within those settings. Mental image (affect, cognition), anticipated behaviour, and design elements in public space are defined from previous research and mapped using facet theory to represent the hypothesised configuration. With this framework, connections between physical settings and behaviour are explored, with the hypothesis that anticipated behaviour in public space is defined by the affective and cognitive images of the physical setting.

\section{Method}

\subsection{Participants}

The participants were 160 stationary users of four public spaces in the city centre of Wellington, New Zealand. Two participants were excluded due to incomplete data. The 158 included respondents compromised 77 male, 78 female, and 3 unspecified, aged between 14 and 64 
years with a mean age of 31.8 years. The sample was 61.4\% NZ European, 13.9\% European, 8.9\% Asian, 3.8\% Māori, 4.4\% other (African, Middle Eastern, Latin) ethnicity and $7.6 \%$ not specified. The average length of time living in Wellington was 10 years. $67.7 \%$ had tertiary education, $6.3 \%$ trade qualifications and $23.4 \%$ secondary qualifications. $53.8 \%$ work in the city centre and $65 \%$ use public space more than 2 or 3 days a week. Times of data collection were spread evenly across the four locations and represented different times of the day (morning, lunchtime, afternoon) split between workdays and weekends.

\subsection{Questionnaire Design}

The questionnaire design was framed using the facet theory (Borg \& Shye, 1995; Canter, 2012; Hackett, 2014). Originally proposed by Guttman in 1954, facet theory uses a mapping sentence to provide a direct link between a theoretically derived hypothesis and the results of the empirical research. This sentence specifies the range of response for the population of interest and when resulting data is analysed (see Section 4.3 on data analysis), this enables the theoretical argument to be directly evaluated using the results of the data analysis (Guttman, 1968, 1982).

The research hypothesis specified affect, cognition, physical setting, and behaviour as four facets in the theory of place in public space. A comprehensive literature review identified a list of elements that will affect the social life of public space. The list was narrowed down to cover only the critical elements. These facets and the elements within each facet are defined as follows:

1. Physical setting $(2 \times 3=6$ elements): Studies have linked the visual character of nature, like form and texture, to the quality of environments and people's preferences within it (Kaplan, 1987; Ulrich, 1983). Incorporating natural design elements like grass, trees, and water contributes to individual and group activity in public spaces (Appleyard, 1978; Knecht, 2004; Taylor, Kuo, \& Sullivan, 2002; Ulrich, 1983). In defining physical setting, material type (natural or artificial) is combined with three representative design elements of public space, furniture, surfaces, and features (Motloch, 2000). This combination of material type and design elements defines six elements in the physical setting facet.

2. Affect (2 elements): Affect is described in two primary dimensions-pleasantness and arousal (Russell \& Pratt, 1980). The combination of pleasantness and arousal gives rise to a feeling of excitement while pleasant and low arousal is relaxing. Unpleasant arousal brings distress, with unpleasant low arousal gloomy (Yik, Russell, \& Steiger, 2011). In public space, relaxing spaces are pleasant, peaceful, and tranquil, and exciting spaces are interesting and energising. Based on the work of Russell and Pratt (1980) and Yik et al. (2011), relaxing and exciting were used to define two elements in the affect facet. These elements represent the positive activation of affect with negative deactivations indicated by participant ratings on the response scale.

3. Cognition (2 elements): In defining urban cognition, Nasar (1989) refers to Lynch's (1960) concept of imageability through which people build knowledge in public space. The two important cognitive components of imageability are legibility and meaningfulness (Gifford, 2014; Montgomery, 1998; Nasar, 1994). A space is legible when it has an obvious arrangement and clear structure, and meaningful when its identity holds a special character for the person. Pilot testing of questionnaire items found clear identity and obvious arrangement were not immediately understood by respondents. More detailed discussions revealed that clear structure and special character are better terms to express legibility and meaningfulness.

4. Behaviour (2 elements): Comparisons involving both emotional bonds to the setting and the activities afforded by the setting come into play when circumstances heighten awareness (Stokols \& Shumaker, 1981). Gehl (1987) and Lennard and Lennard (1995) categorised the two extended types of activity in public space as being alone or being with friends and family. Gehl (1987) sorted activities in terms of intensity, from simple noncommunal contacts (being alone and seeing and hearing people) to complex and emotionally involved connections (being with friends and family). Similarly, Lennard and Lennard (1995) grouped social life in a public place through connections to others without speech and being in public in a group. For the behaviour facet, behaviour is divided into two types, whether meeting a group of friends in a public space or spending time alone in a public space.

The inter-relationships between behaviour, physical setting, and mental image is defined for the population of interest, users of small urban public spaces, with affect and cognition represented by separate facets of the mental image. The mapping sentence (Figure 1 ) specifies 48 items in a $2 \times(2 \times 3) \times 2 \times 2$ combination of elements in facets. A typical item is: "When I spend time with my friends in public spaces, I prefer places with wood and stone furnishings because the place is relaxing and has a clear identity". The 48 items were presented in two sections of 24 items in the questionnaire as specified by the behaviour facet (being alone or with friends). Written instructions explaining this division were provided. Responses to each of the 48 items were indicated on sevenpoint Likert scales ranging from (1) strongly disagree to (7) strongly agree. 


$$
\text { When I spend time } \left.\left.\begin{array}{c}
\text { Behaviour } \\
\text { with } \mathrm{my} \\
\text { friends } \\
\text { by myself }
\end{array}\right) \text { in public spaces, } \begin{array}{c}
\text { Design Elements } x \text { Materials } \\
\text { wood and stone furnishings } \\
\text { plastic and metal furnishings } \\
\text { grass, stone or wooden surfaces } \\
\text { painted, concrete or tiled surfaces } \\
\text { trees, water and plant features } \\
\text { sculptures, artifacts and decorative features }
\end{array}\right)
$$

$$
\begin{aligned}
& \text { Affect Cognition } \\
& \text { because the place is }\left[\begin{array}{c}
\text { relaxing } \\
\text { exiciting }
\end{array}\right] \text { and has a }\left[\begin{array}{c}
\text { clear structure } \\
\text { special character }
\end{array}\right]
\end{aligned}
$$

Figure 1. The mapping sentence used in the survey of stationary users.

Specific examples of design elements or behaviour were excluded from the facets to reduce the influence of individual differences in preferences. For example, if natural is tropical for one person and a manicured garden to another, the inclusion of specific examples would confound the results. The first would prefer small urban public spaces with lush tropical vegetation and not be interested in meeting friends or going alone to a space with organised gardens. The decision-making process of each user would be the same, but the outcome of the process in a specific context would be different. A positive affect in one context would frame the cognitive appraisal and preference for the space while a negative affect in another space would result in a lower preference for that space. This pattern would reverse for the second respondent. The process would be consistent, but the data would be different. By using sparse descriptions, respondents drew on their experience to answer each question and the group average results are indicative of a consistent process used by each participant.

\subsection{Data Analysis}

The influence of individual differences in experience is controlled in the present research by interviewing stationary users of public space with a generic questionnaire. The questionnaire does not ask them about the public space, their current activity, or indicate what they might do if meeting friends or spending time in a public space. Their presence indicates a shared preference for using public space in the urban core. The group average response is analysed using non-metric MultiDimensional Scaling (MDS) with each item represented as a point in a multidimensional Euclidean space. Within this space, items having similar response patterns are grouped closer together with the relative locations of items providing a graphical representation of the similarity or dissimilarity of each item to all other items. Regions within the spatial representation are defined by elements which share similar item response patterns. This visual description of the data structure is further informed using mean preference ratings for each item and non-parametric statistical tests (Friedman's $\chi^{2}$ ) to assess differences between regions (Groves \& Wilson, 1993).

\section{Results}

The two-dimensional spatial representation of 48 questionnaire items is described by the naturalness or artificiality of design elements (Figure 2). With the artificial design elements, the 24 items depict three subgroupings: artificial furnishing (plastic, metal), artificial surfaces (painted, concrete or tiled), and artificial features (sculpture, artefacts, decorative). There is a separation between being alone or with friends with artificial furnishings and artificial surfaces. The eight items relating to artificial features are proximal to the 24 natural items. With the natural items, the separation between design elements, and the separation between being alone or with friends, not as distinct with natural surfaces (grass, stone, wood) and natural features (trees, water, plants) inter-related.

The preference ratings of natural and artificial design elements, broken down by behaviour and site (see Table 1) indicated a preference for natural design elements (median $=130.5$ ) over artificial design elements (median $=96$; Friedman $\chi^{2}=131.9, d f=1$, $N=158, p<0.000)$. This preference for natural design elements was significant on weekdays $\left(\chi^{2}=72.053\right.$, $p<0.000)$, weekends $\left(\chi^{2}=60.266, p<0.000\right)$, if alone $\left(\chi^{2}=134.427, p<0.000\right)$ or with friends $\left(\chi^{2}=120.695\right.$, $p<0.000)$.

With both the natural and artificial design elements, features receive the highest preference, followed by surfaces, with furnishings given the lowest rating. This result is observed overall and in 30 of the 32 ratings on workdays and weekends for each site. Artificial surfaces and artificial furnishings receive an overall negative rating (i.e., means $<$ four).

1. A significant difference between natural features ( median $=48)$, surfaces (median $=44)$, and furnishings (median $=40 ; \chi^{2}=122.015, d f=2$, $\mathrm{N}=158, p<0.000$ ). Post-hoc pairwise compar- 


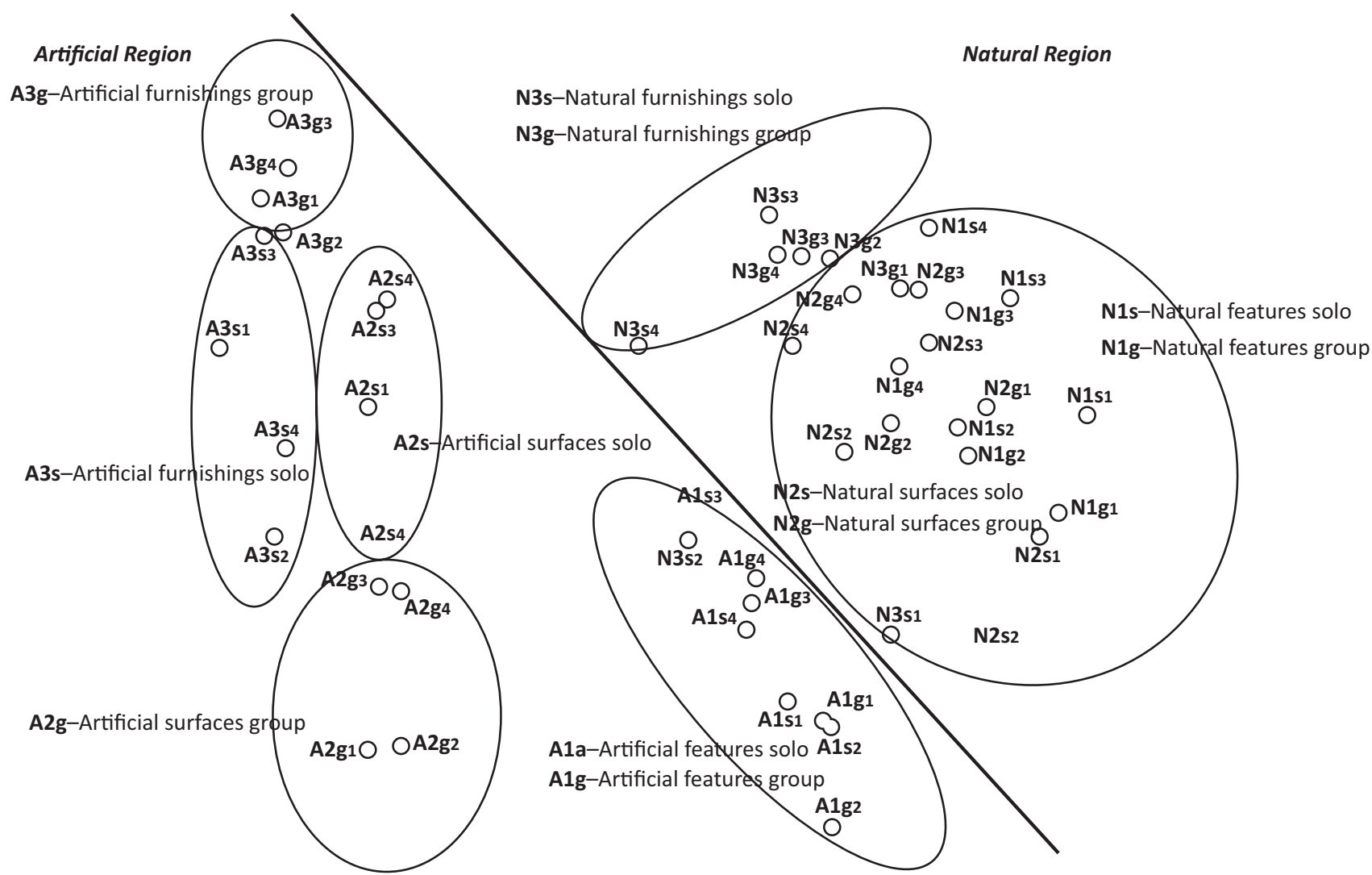

Figure 2. Two-dimensional spatial representation of 48 items (stress $=0.07 ; N=158$ ).

isons using Wilcoxon found the median preference for natural features was significantly greater than the median preferences for natural surfaces $(p<0.000)$ and furnishings $(p<0.000)$, and the median preference for natural surface significantly greater than the median preference for natural furnishing $(p<0.000)$.

2. With artificial design elements, a significant difference was found between artificial features (median $=40)$, surfaces (median $=31.5)$, and furnishings (median $=28 ; \chi^{2}=149.247, d f=2, N=158$, $p<0.000$ ). Post-hoc pairwise comparisons using Wilcoxon found the median preference for artificial feature was significantly greater than the median preference for surface $(p<0.000)$ and furnishing $(p<0.000)$, and the median preference for surface significantly greater than the median preference for furnishing $(p<0.000)$.

With the overall preference for natural design elements over artificial elements and statistical difference between types of design elements, separate analyses were conducted for natural and artificial elements. In the twodimensional spatial representation of the 24 natural design elements (Figure 3 ), behaviour is described by mental image (affect, cognition) and type of design element. The spatial representation of data points from the upper left to the lower right reflects overall preferences with natural features preferred, followed by natural sur- faces and natural furnishings (see Table 1). Within this ordering, design elements are distinguished by mental image. Three regions are evidenced: (1) natural design elements that have a "relaxing and special character" (lower left ellipse), (2) an intertwined middle grouping of "relaxing and clear structure" and "exciting and special character", and (3) design elements "exciting and clear structure" (upper right ellipse). Although preferences for natural features, surfaces, and furnishings were found to be different (see Table 1), natural design elements with "relaxing and special character" are preferred for solo and group activity. Natural design elements with an "exciting and clear structure" are less preferred than natural design elements that have an "exciting and special character" or "relaxing and clear structure" (see Table 2). Nested within this two-dimensional mental image of natural design features, the separation between the four affective-cognitive combinations for solo activity is greater than the separation between design elements for group activity.

In the analysis of the 24 artificial design elements, differences between features, surfaces, and furnishings are greater than mental images (affective, cognitive) of solo or group activity (Figure 4). The mean preference ratings decrease from left to right and there is no separation within artificial furnishings and artificial surfaces based on their affective-cognitive evaluations. With artificial features which received positive preference ratings (Table 1 ) and were closer to the natural design ele- 
Table 1. Mean preference of natural and artificial design elements.

\begin{tabular}{|c|c|c|c|c|c|c|c|c|}
\hline & \multicolumn{4}{|c|}{ Alone } & \multicolumn{4}{|c|}{ With Friends } \\
\hline & \multicolumn{2}{|c|}{ Natural } & \multicolumn{2}{|c|}{ Artificial } & \multicolumn{2}{|c|}{ Natural } & \multicolumn{2}{|c|}{ Artificial } \\
\hline & Workdays & Weekends & Workdays & Weekends & Workdays & Weekends & Workdays & Weekends \\
\hline \multicolumn{9}{|c|}{ Midland Park } \\
\hline Furnishings & 4.86 & 4.93 & 3.76 & 2.76 & 5.35 & 5.60 & 3.76 & 2.81 \\
\hline Surfaces & 5.49 & 5.56 & 4.10 & 3.39 & 5.63 & 5.85 & 3.96 & 2.95 \\
\hline \multirow[t]{2}{*}{ Features } & 5.99 & 6.30 & 5.19 & 4.96 & 5.96 & 6.23 & 5.11 & 5.06 \\
\hline & 5.45 & 5.60 & 4.35 & 3.70 & 5.65 & 5.89 & 4.28 & 3.61 \\
\hline \multicolumn{9}{|l|}{ Glover Park } \\
\hline Furnishings & 4.86 & 4.74 & 3.32 & 2.34 & 5.21 & 4.77 & 3.34 & 2.46 \\
\hline Surfaces & 5.42 & 5.41 & 3.53 & 2.83 & 5.34 & 5.35 & 3.93 & 3.40 \\
\hline \multirow[t]{2}{*}{ Features } & 5.68 & 6.06 & 4.80 & 5.08 & 5.86 & 5.40 & 4.87 & 5.06 \\
\hline & 5.32 & 5.40 & 3.88 & 3.41 & 5.47 & 5.17 & 4.05 & 3.64 \\
\hline \multicolumn{9}{|l|}{ Civic Square } \\
\hline Furnishings & 5.01 & 4.91 & 3.63 & 3.23 & 5.00 & 5.05 & 3.49 & 3.04 \\
\hline Surfaces & 5.50 & 5.29 & 3.54 & 3.87 & 5.43 & 5.49 & 3.70 & 3.89 \\
\hline \multirow[t]{2}{*}{ Features } & 5.87 & 6.03 & 5.08 & 4.61 & 5.82 & 5.50 & 5.34 & 4.71 \\
\hline & 5.46 & 5.41 & 4.08 & 3.90 & 5.42 & 5.35 & 4.18 & 3.88 \\
\hline \multicolumn{9}{|l|}{ Te Aro Park } \\
\hline Furnishings & 4.76 & 4.79 & 3.33 & 3.33 & 4.96 & 5.06 & 3.06 & 3.61 \\
\hline Surfaces & 5.56 & 5.60 & 3.92 & 3.59 & 5.60 & 5.43 & 3.95 & 3.75 \\
\hline \multirow[t]{2}{*}{ Features } & 5.79 & 5.48 & 5.00 & 4.87 & 6.00 & 5.66 & 5.19 & 5.09 \\
\hline & 5.37 & 5.29 & 4.08 & 3.93 & 5.52 & 5.38 & 4.07 & 4.15 \\
\hline \multicolumn{9}{|l|}{ Overall } \\
\hline Furnishings & 4.87 & 4.84 & 3.51 & 2.91 & 5.13 & 5.12 & 3.41 & 2.98 \\
\hline Surfaces & 5.49 & 5.47 & 3.78 & 3.42 & 5.50 & 5.53 & 3.89 & 3.50 \\
\hline \multirow[t]{2}{*}{ Features } & 5.83 & 5.97 & 5.02 & 4.88 & 5.91 & 5.70 & 4.96 & 4.98 \\
\hline & 5.40 & 5.42 & 4.10 & 3.74 & 5.51 & 5.45 & 4.14 & 3.82 \\
\hline
\end{tabular}

Table 2. Mental image of design elements.

\begin{tabular}{|c|c|c|c|c|c|c|c|c|}
\hline & \multicolumn{4}{|c|}{ Alone } & \multicolumn{4}{|c|}{ With Friends } \\
\hline & \multicolumn{2}{|c|}{ Relaxing } & \multicolumn{2}{|c|}{ Exciting } & \multicolumn{2}{|c|}{ Relaxing } & \multicolumn{2}{|c|}{ Exciting } \\
\hline & $\begin{array}{c}\text { Special } \\
\text { Character }\end{array}$ & $\begin{array}{c}\text { Clear } \\
\text { Structure }\end{array}$ & $\begin{array}{c}\text { Special } \\
\text { Character }\end{array}$ & $\begin{array}{c}\text { Clear } \\
\text { Structure }\end{array}$ & $\begin{array}{c}\text { Special } \\
\text { Character }\end{array}$ & $\begin{array}{c}\text { Clear } \\
\text { Structure }\end{array}$ & $\begin{array}{c}\text { Special } \\
\text { Character }\end{array}$ & $\begin{array}{c}\text { Clear } \\
\text { Structure }\end{array}$ \\
\hline Natural Furnishings & 5.39 & 4.97 & 4.64 & 4.42 & 5.46 & 5.01 & 5.14 & 4.90 \\
\hline Natural Surfaces & 6.10 & 5.59 & 5.25 & 4.97 & 5.84 & 5.53 & 5.44 & 5.25 \\
\hline \multirow[t]{2}{*}{ Natural Features } & 6.40 & 5.97 & 5.77 & 5.47 & 6.20 & 5.72 & 5.81 & 5.48 \\
\hline & 5.96 & 5.51 & 5.22 & 4.95 & 5.83 & 5.42 & 5.46 & 5.21 \\
\hline Artificial Furnishings & 2.96 & 3.25 & 3.30 & 3.32 & 3.10 & 3.20 & 3.24 & 3.23 \\
\hline Artificial Surfaces & 3.57 & 3.59 & 3.66 & 3.56 & 3.64 & 3.61 & 3.75 & 3.75 \\
\hline \multirow[t]{2}{*}{ Artificial Features } & 5.04 & 4.73 & 5.21 & 4.82 & 5.18 & 4.85 & 5.26 & 4.92 \\
\hline & 3.86 & 3.85 & 4.06 & 3.90 & 3.97 & 3.89 & 4.08 & 3.97 \\
\hline
\end{tabular}




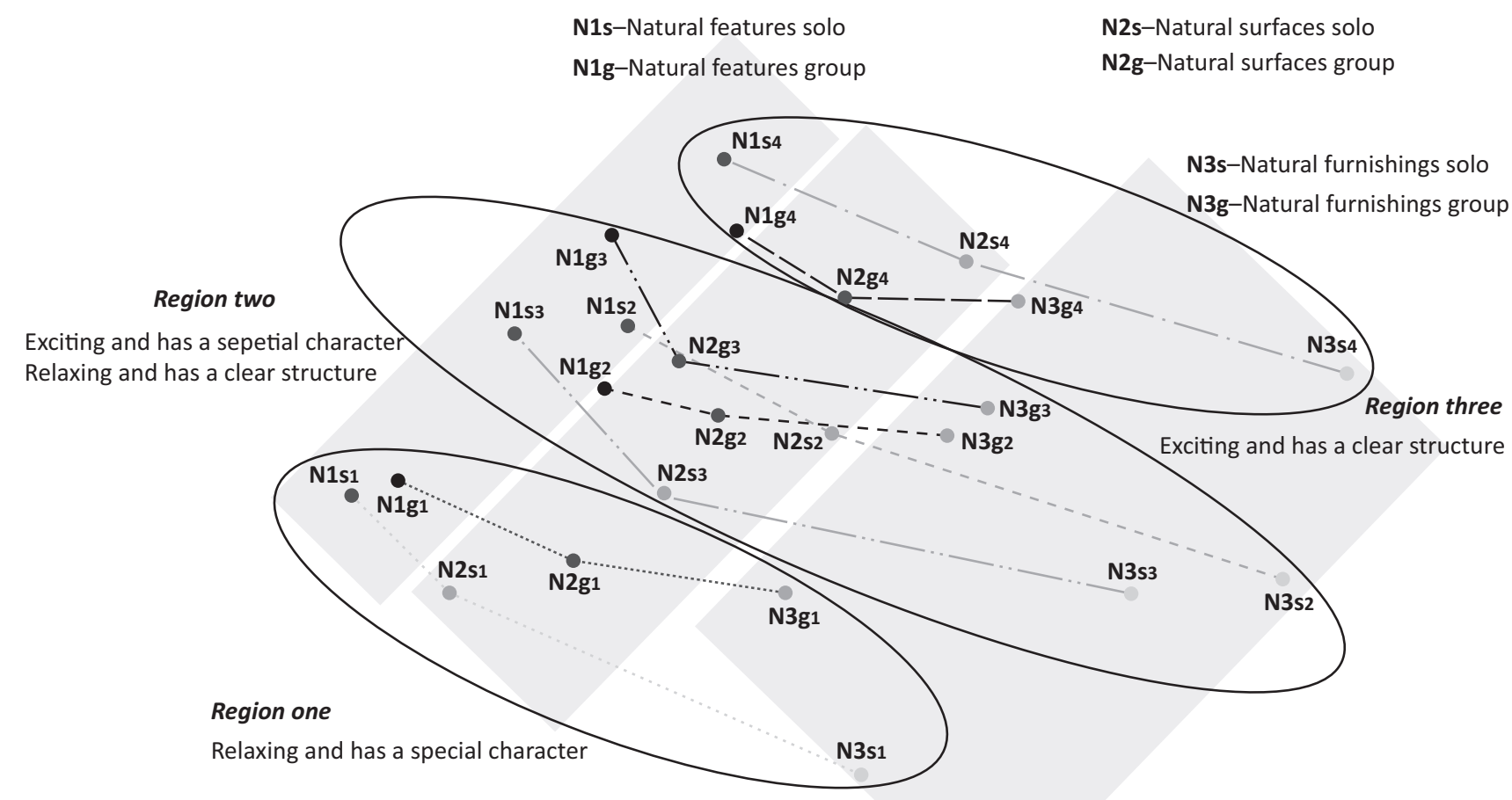

Figure 3. Two-dimensional spatial representation of 24 natural design elements classified by design feature, behaviour, and cognitive-affective affordance (stress $=0.14 ; \mathrm{N}=158$ ). Grey areas represent the three design elements, features, surfaces and furnishings.

\section{Region one}

A1-Artificial surfaces

Relaxing and has a clear structure

Exciting and has a clear structure
Region three

A3-Artificial furnishings

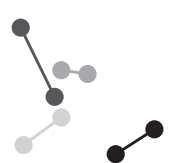

\section{Region two}

A2-Artificial surfaces

Relaxing and has a special character

Exciting and has a special character

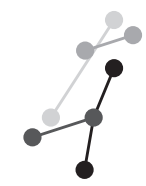

Figure 4. Two-dimensional spatial representation of 24 artificial items classified according to mental image (stress $=0.05$; $\mathrm{N}=158)$. 
ments in the overall analysis (Figure 2), artificial features with a "special character" are preferred to those with a "clear structure".

\section{Discussion}

The research conducted in four public spaces found that the affective and cognitive processing of natural and artificial design elements in public space described preferences for solo and group activity; that relaxing spaces with natural design elements are preferred when individuals anticipate meeting friends in public space or spending time in public space. While artificial surfaces and furnishings received negative evaluations, artificial features with special character are a positive focus for individual and group activity. For solo users, the experience in the space is important with the character of space being more important than its structure. When meeting friends, furniture and elements with character and structure are preferred, indicating that usability and functionality of space is evaluated. These findings evidence Rapoport (1982) and Motloch's (2000) arguments, and research on place dependence that both the affective and cognitive process are involved, with the affective image of the physical setting providing a gateway to the cognitive appraisal of design elements and/or the character of the setting for anticipated behaviour.

The description of physical settings and behaviour defined and measured using a mapping sentence described a system operating as if these linguistic constructs exist and interact. An interpretation of a system configuration which argued theoretically is evidenced through results of data (Norman, 1986); an evidence base predicated by the assumption that measurement of the hypothesis is achieved with the linguistic manipulations. This is an assumption of not only the present research, but also of surveys that permeate place-making design tools, and more general studies of people-environment interactions which use questionnaires. Researches on manipulations of linguistic scales which assess affective and cognitive responses to physical settings have reported consistent within task evaluations and systematically different evaluations between tasks (Ward \& Russell, 1981). In these findings, within tasks, differences are treated as errors of measurement and average response patterns are presented as indicative of the sampled population's mental image. While Ward and Russell (1981) argued that the differences between the evaluations indicated that mental representation of meaning is complex, Daniel and Ittelson (1981, p. 153) noted that these tasks "consistently reproduce their own a priori semantic structure", a within-group consistency which is an artefact of the measurement task; a top-down cognitive constraint of linguistic manipulations with commonly understood definitions. However, when the analyses of tasks compared individual response patterns, individual differences in affect responses were greater than the within-task similarities in affect (Groves, 1992; Groves \& Clutton, 1990).
Pleasant, relaxing, exciting, etc., are linguistic categories defined through lived experiences with ratings on the response scale reflecting idiosyncrasies of accumulated experiences. The constraints of an affect response task direct individuals to draw on their lived experience; experiences which can overlap with shared cultural, social, and educational histories; experiences which can be influenced by marketing but are uniquely lived and ongoing. Affect scales provide a methodological window to access individual's mental images which are pivotal to their use or non-use of public space, the subspaces within and design elements within subspaces. Dimensions of pleasant, relaxing, exciting or unpleasant provide important descriptions of settings, but are also important for the comparisons they provide between settings.

\section{Conclusion}

Places are "far more than interesting groups of buildings, or well-formed street spaces" or "foci of social and economic enterprises" (Relph, 1993, p. 37). Places are spaces where possibilities exist for territories of diverse meanings in support of chosen activities. Designers provide direction and advice and become objective participants in on-going processes of place-making with skills "to resolve specific technical matters, overcome parochialism, and see the broader effects and implications of local actions" (Relph, 1993, p. 34). With theory and practice, place-making in practice can transform spaces into places, creating socio-spatial settings connecting people individually and personally with space (Dovey, 2016), providing scope for "modifications, additions and changes in social behaviour" (Relph, 1993, p. 36), expressions providing a more sustainable approach to the design of public space.

With technological and social changes, travel, and economic and cultural globalisation, spaces are open to a world of interpretations, with each experience a specific focus of meanings and activities for every visitor in the space (Relph, 2016). With their use or non-use of space, a choice defined in a two-stage process where a summation of experience frames cognitive evaluations of design elements for anticipated behaviour. If the initial response is negative in the respondent's framework (which research can access through measurement of differences between ideal and current affect), this rejection of space will render any cognitive evaluation of design elements unnecessary. Based on their experience, they may exclude or include the space from consideration. However, such decisions are not necessarily fixed, and choices and evaluations can change over time because experience is accumulated and on-going. It is this temporal dimension of meaning based on individuals' accumulated experience which suggests place-making in design should shift emphases from prescriptive articulations of preferences assessed at a point in time to enabling opportunity and interpretation for different users and for change over time. 
At present, consultations with stakeholders (users, owners, governments) in the planning and design phase of place-making are used to align chosen activities with design opportunities (Cilliers \& Timmermans, 2014), a process which ensures stakeholder support and acceptance for public expenditure (Carmona, 2010; Strydom \& Puren, 2013). While the design interpretation of data collected at a point in time may prove initially popular because expectations and design are aligned, this popularity can fade over time with changes in expectations. Akin to theatre halls without new shows or art galleries without new exhibits, on-going expenditures on marketing and promotion of activities is required to generate use, reuse and attract new users. Once-popular places can to return to placeless spaces requiring another redevelopment. A circularity born of design practices where participant data and design interpretation is aligned with a participatory methodology in isolation from a theoretical framework of place.

\section{Acknowledgments}

An earlier version of this article was presented at The Future of Place Conference III, June 2015, Stockholm, Sweden (http://futureofplaces.com).

\section{Conflict of Interests}

The authors declare no conflict of interests.

\section{References}

Appleyard, D. (1978). Urban trees, urban forests: What do they mean? Paper presented at the National Urban Forestry Conference, State University of New York College, New York.

Borg, I., \& Shye, S. (1995). Facet theory: Form and content. Thousand Oaks, CA: Sage.

Canter, D. (1997). The facets of place. In G. T. Moore \& R. W. Marans (Eds.), Advances in environment, behaviour and design: Toward the integration of theory, methods, research, and utilization (Vol. 4, pp. 109-147). Boston, MA: Springer.

Canter, D. (2008). Do we need a meta-theory of the built environment? Building Research \& Information, 36(6), 663-667.

Canter, D. (Ed.). (2012). Facet theory: Approaches to social research. Berlin: Springer Science \& Business Media.

Carmona, M. (2010). Public places, urban spaces: The dimensions of urban design (2nd ed.). Oxford: Architectural Press.

Carmona, M. (2015). Re-theorising contemporary public space: A new narrative and a new normative. Journal of Urbanism: International Research on Placemaking and Urban Sustainability, 8(4), 373-405.

Cilliers, E. J., \& Timmermans, W. (2014). The importance of creative participatory planning in the public place- making process. Environment and Planning B: Planning and Design, 41(3), 413-429.

Daniel, T. C., \& Ittelson, W. H. (1981). Conditions for environmental perception research: Comment on "The psychological representation of molar physical environments" by Ward and Russell. Journal of Experimental Psychology: General, 110(2), 153-157.

Dixon, N. F. (1981). Preconscious processing. New York, NY: John Wiley \& Sons.

Dovey, K. (2016). Place as multiplicity. In R. Freestone \& E. Liu (Eds.), Place and placelessness revisited (pp. 257-268). New York, NY: Routledge.

Gehl, J. (1987). Life between buildings: Using public space. Washington, DC: Island Press.

Ghavampour, E., Del Aguila, M., \& Vale, B. (2017). GIS mapping and analysis of behaviour in small urban public spaces. Area, 49(3), 349-358.

Gifford, R. (2014). Environmental psychology matters. Annual Review of Psychology, 65(1), 541-579.

Groves, M. A. (1992). Beyond spatial representation. Quality and Quantity, 26(1), 49-59.

Groves, M. A., \& Clutton, S. (1990). Measurement task effects in environmental cognition research. People and Physical Environment Research, 33, 16-21.

Groves, M. A., \& Wilson, V. F. (1993). To move or not to move? Factors influencing the housing choice of elderly persons. Journal of Housing for the Elderly, 10(1/2), 33-47.

Guttman, L. (1954). An outline of some new methodology for social research. Public Opinion Quarterly, 18(4), 395-404.

Guttman, L. (1968). A general nonmetric technique for finding the smallest coordinate space for a configuration of points. Psychometrika, 33(4), 469-506.

Guttman, L. (1982). What is not what in theory construction. In R. M. Hauser, D. Mechanic, \& A. Haller (Eds.), Social structure and behavior (pp. 331-348). New York, NY: Academic Press.

Hackett, P. M. (2014). Facet theory and the mapping sentence: Evolving philosophy, use and application. London: Palgrave Macmillan.

Kaplan, S. (1987). Aesthetics, affect, and cognition environmental preference from an evolutionary perspective. Environment and Behavior, 19(1), 3-32.

Kaplan, S. (1995). The restorative benefits of nature: Towards an integrative framework. Journal of Environmental Psychology, 15(3), 169-182.

Knecht, C. (2004). Urban nature and well-being: Some empirical support and design implications. Berkeley Planning Journal, 1, 82-108.

Lennard, S. H. C., \& Lennard, H. L. (1995). Livable cities observed: A source book of images and ideas for city officials, community leaders, architects, planners and all other committed to making their cities livable. Carmel, CA: Gondolier Press.

Lewicka, M. (2011). Place attachment: How far have we come in the last 40 years? Journal of Environmental Psychology, 31(3), 207-230. 
Liu, E., \& Freestone, R. (2016). Revisiting place and placelessness. In R. Freestone \& E. Liu (Eds.), Place and placelessness revisited (pp. 1-19). New York, NY: Routledge.

Lynch, K. (1960). The image of the city. Cambridge, MA: MIT Press.

Montgomery, J. (1998). Making a city: Urbanity, vitality and urban design. Journal of Urban Design, 3(1), 93-116.

Motloch, J. L. (2000). Introduction to landscape design (2nd ed.). New York, NY: Wiley.

Nasar, J. L. (1989). Perception, cognition, and evaluation of urban places. In I. Altman \& E. H. Zube (Eds.), Public places and spaces (Vol. 10, pp. 31-56). New York, NY: Plenum Press.

Nasar, J. L. (1994). Urban design aesthetics: The evaluative qualities of building exteriors. Environment \& Behavior, 26(3), 377-401.

Norman, D. A. (1986). Reflections on cognition and parallel distributed processing. In J. L. McClelland \& D. E. Rumelhart (Eds.), Parallel distributed processing (Vol. 2). Cambridge, MA: MIT Press.

Pretty, G. H., Chipuerb, H. M., \& Bramston, P. (2003). Sense of place amongst adolescents and adults in two rural Australian towns: The discriminating features of place attachment, sense of community and place dependence in relation to place identity. Journal of Environmental Psychology, 23(3), 273-287.

Rapoport, A. (1982). The meaning of the built environment: A nonverbal communication approach. Beverly Hills, CA: Sage.

Relph, E. C. (1976). Place and placelessness. London: Pion.

Relph, E. C. (1993). Modernity and the reclamation of place. In D. Seamon (Ed.), Dwelling, seeing and designing: Toward a phenomenological ecology (pp. 25-40). Albany, NY: State University of New York Press.

Relph, E. C. (2016). Afterword. In R. Freestone \& E. Liu (Eds.), Place and placelessness revisited (pp. 295-298). New York, NY: Routledge.

Russell, J. A., \& Pratt, G. (1980). A description of the affective quality attributed to environments. Journal of
Personality and Social Psychology, 38(2), 311-322.

Scannell, L., \& Gifford, R. (2010). Defining place attachment: A tripartite organizing framework. Journal of Environmental Psychology, 30(1), 1-10.

Stedman, R. (2003). Is it really just a social construction? The contribution of the physical environment to sense of place. Society and Natural Resource, 16(8), 671-685.

Stokols, D., \& Shumaker, S. A. (1981). People in places: A transactional view of settings. In J. Harvey (Ed.), Cognition, social behavior, and the environment (pp. 441-488). Hillsdale, NJ: Erlbaum.

Strydom, W., \& Puren, K. (2013). A participatory approach to public space design as informative for placemaking. Challenges of Modern Technology, 4, 33-40.

Taylor, A. F., Kuo, F. E., \& Sullivan, W. C. (2002). Views of nature and self-discipline: Evidence from inner city children. Journal of Environmental Psychology, 22(1/2), 49-63.

Ulrich, R. S. (1983). Aesthetic and affective response to the natural environment. In I. Altman \& J. F. Wohlwill (Eds.), Human behavior and environment: Advances in theory and research (Vol. 6, pp. 85-125). New York, NY: Plenum Press.

Wagner, P. L. (1972). Environments and peoples. Englewood Cliffs, NJ: Prentice Hall.

Ward, L. M., \& Russell, J. A. (1981). The psychological representation of molar physical environments. Journal of Experimental Psychology: General, 110(2), 121-152.

Yik, M., Russell, J. A., \& Steiger, J. H. (2011). A 12-point circumplex structure of core affect. Emotion, 11(4). 705-731.

Zajonc, R. B. (1980). Feeling and thinking: Preferences need no inferences. American Psychologist, 35(2), 151-175.

Zhang, H., Matsuoka, R. H., \& Huang, Y. J. (2018). How do community planning features affect place relationship of residents? An investigation of place attachment, social interaction and community participation. Sustainability, 10(8), 272.

\section{About the Authors}

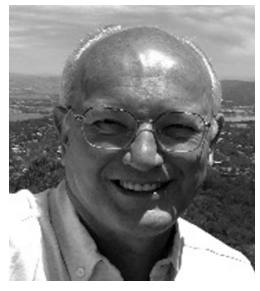

Mark del Aguila, PhD, is joint Co-Ordinator of the Gerontology Network for the International Association of People Environment Studies (IAPS). He has published in gerontology, technology, environmental psychology, and multivariate descriptive statistics.

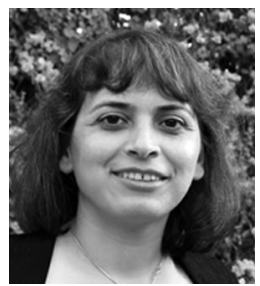

Ensiyeh Ghavampour, PhD, is the founder and Director of Urban Entrepreneur, with a vision to address loneliness in suburban communities through co-design and activation of public spaces. She holds a PhD in Urban Design and a master's degree in landscape architecture. She has experience working with educational institutes, public and private sectors across Iran and New Zealand. Her current research focuses on placemaking, public open space, participatory design and loneliness. 


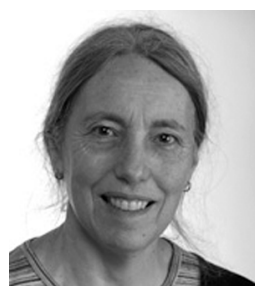

Brenda Vale, PhD, is Professional Research Fellow at Victoria University of Wellington. Brenda is an architect, academic and co-author of several books on the topic of sustainable design and ecological footprint. Brenda and her husband Robert Vale have jointly designed an award-winning commercial building in the UK, the UK's first autonomous house, and the first zero-emissions settlement and have received international awards, including those from the United Nations and European Solar Energy Society. They developed the Australian government's National Australian Built Environment Rating System. 